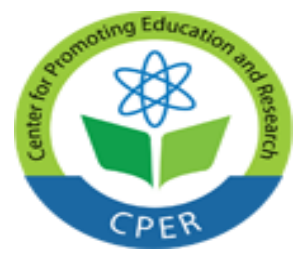

VOL: 5, ISSUE: 3

March/2019

https://ijbassnet.com/

E-ISSN: 2469-6501

(C) Center for Promoting Education and Research (CPER) USA

WWW.cpernet.org

\title{
The Perception of Cooperative Learning in Teaching and Learning in Malaysia High School
}

\author{
Ahmad Fahim Zulkifli ${ }^{1}$ \\ Faculty of Education \\ Universiti Teknologi MARA, \\ 42300 Bandar Puncak Alam \\ Selangor, Malaysia \\ Phone: +601111472156 \\ Email: fahimzulkifli@uitm.edu.my \\ Malaysia \\ Muhammad Fikri Ariff Adnan \\ Faculty of Education \\ Universiti Teknologi MARA, \\ 42300 Bandar Puncak Alam \\ Selangor, Malaysia
}

\begin{abstract}
Study aim: The purpose of this study was to investigate the perception of cooperative learning in teaching and learning in Malaysia High School.

Materials and methods: This study emphasized on teachers' views on cooperative learning approach to support their students' teaching and learning in classroom. The study uses the qualitative approach involving 10 academic staff of a local secondary school located at Subang Jaya, Selangor by using semi structured interview method.

Results: The findings showed positive perceptions and interest towards the cooperative learning approach in teaching and learning in secondary schools.

Conclusions: There were many advantages of cooperative learning in teaching and learning both for staff and students. The cooperative learning should be implemented in classroom as it may help students to better link between the concepts and real world. Therefore, educators should invest considerable time to learn about this concept and plan their teaching and learning around their learners.
\end{abstract}

Keywords: Collaborative learning, teaching and learning, student-centered approach, learning strategies.

\section{INTRODUCTION}

There are many learning strategies based on students-centered approach that educator could use in a classroom during teaching and learning with the students. The learning strategies should be use according to the situation and students' background (e.g., strength, weaknesses, interests). Some alternative learning strategies includes the discussion learning strategy, games learning strategy, and cooperative learning strategy.

In a study by Johnson, Johnson and Smith (2007); McWilliams, Malecha, Langford and Clutter (2017), cooperative learning is a learning strategy based on the social theory which emphasized on social interaction and active learning between students. Students nowadays are far more technological advance from the previous

${ }^{1}$ Ahmad Fahim Zulkifli corresponding author 


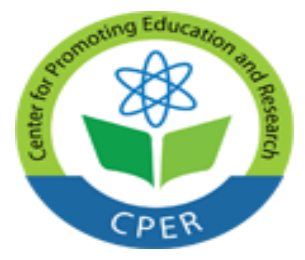

VOL: 5, ISSUE: 3

March/2019

E-ISSN: 2469-6501

(C) Center for Promoting Education and Research (CPER) USA

WWW.cpernet.org

generations. Therefore, they need new way of learning the subject matter and activities that help them to remain focus and give full attention during the class. Study focus on practice time and cooperative learning approach also founded visible and statistically significant improvement on students' interest towards learning (Bahadir, 2011).

According to Chai, Tay, and Lim (2015), cooperative learning is a learning strategy that require students to form groups or partners to learn the subject more effectively. They also added the learning style contributed in improving the students' soft skills which are communication, teamwork, and decision-making. Cooperative learning is better than the traditional learning as students' have more opportunity to improve their knowledge and skills by engaging in discussion with their group and discuss the topic given. Thus, the students are given more learning ownership and help their peers to enhance their understanding and achieving set goals through group discussion (Demirham \& Altay, 2001).

The educators are mainly responsible as the leader in the classroom should have the initiatives in making teaching and learning session more engaging and fun. Nonetheless, in this approach, the educator would assume the role of facilitator. This allows the teacher to spend more time to observe and evaluate their students' learning (Ozgul, Atan, \& Kangalgil, 2019). Consequently, the students can enjoy learning without excessive stress and fear of failure (Huang, Tu, Wang, Chen, Yu, \& Chou, 2017). Additionally, cooperative learning is capable to develop the students' whole learning domains (i.e., psychomotor, cognitive, affective) (Dyson, Griffin, \& Hastie, 2004; Iserbyt, Madou, Vergauwen, \& Behets, 2011).

\section{Purpose}

This study builds on these previous studies to determine the current teachers' perceptions toward cooperative learning in teaching and learning. Therefore, the following research questions were being addressed in this study: (1) what are the current level of interest among teachers to implement cooperative learning?, (2) does cooperative learning provide more advantages compared to traditional teaching and learning, and (3) does teachers perceived the cooperative learning as effective teaching and learning?.

\section{Material and methods}

\section{Participants}

The participants of this study were in-service local high school teachers, there were total of 10 participants with an age range of 28-50 years old. The majority of participants reported a Malay ethnic background with two reporting Chinese and two Indian ethnics backgrounds. Most of the participants orally reported fair experience in student-centered approach and the cooperative learning as part of their teaching and learning process.

\section{Settings}

The Progressive High School (pseudonym) was located in a large suburban area in the central Malaysia. There were 1512 students currently enrolled in the school with 101 teachers responsible for morning and afternoon school sessions.

The teachers' office was the main area used to implement the studies. The group interview session were 30 minutes/sessions. The questions and examples were modified to help teachers relate the cooperative learning concepts with their actual teaching approaches. The researchers prompt teachers with questions and encourages them to engage in the discussion.

\section{Study Design and Procedures}

This study involved teachers' knowledge and perceptions towards student-centered approach and cooperative learning to promote teaching and learning. The data collection lasting for five weeks in between October and 


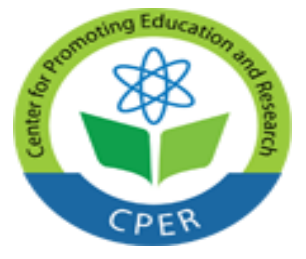

VOL: 5, ISSUE: 3

March/2019

E-ISSN: 2469-6501

(C) Center for Promoting Education and Research (CPER) USA

WWW.cpernet.org

November 2018. This study primarily focuses on accentuating participants' roles during learning and assessing their knowledge and self-efficacy related to cooperative learning.

Prior to the study, the researches were required to obtain approval from the State Education Department, District Education Office, and the school's administrators. The purpose, objectives, and significance of the study were thoroughly explained throughout each of the process. Pseudonym were used to reflects participants' answers and all data were kept confidential for the study purposes. The Institutional Review Board approval was obtained from the school and the teachers provided consent to participate in this study.

\section{Instruments}

Instruments that have shown to produce reliable and valid scores were used for this study. These includes group interviews, sound recorder, and memos to record information. The information gained from the instruments were transcribes and reviewed for trends or themes. Each of the transcripts were cross-checked among researchers to ensure the accuracy of the data.

\section{Data Analysis}

The data collected were transcribes to obtain the important details and categorised into several themes (i.e., perception, interest, advantages, effectiveness). Systematically arranged data were helpful for researchers to analyse the data effectively and produced reliable results (Piaw, 2016).

\section{Results}

These findings were organized into four themes; (1) perception of cooperative learning, (2) level of interest among the participants in implementing cooperative learning, (3) advantages of using cooperative learning, and (4) the effectiveness in using cooperative learning during teaching and learning in classroom.

\section{Perception of Cooperative Learning}

Most of the respondents considered themselves to possessed good knowledge about the cooperative learning concepts. Respondent one explained the cooperative learning is a learning style which involved interaction between group members in solving problems; "I have known cooperative learning as the learning style which encourages the students to work in groups and there was interaction happened between them to identify issues and making collective decisions".

Additionally, respondent two also supported the perception that cooperative learning is a collaborative effort by the students to complete a specific task given by the teacher. The respondent added "cooperative learning is the learning style of the 21st century learning by the Malaysian education system"; "I was introduced to cooperative learning through a course that I attended last year. I knew the learning style since then." For respondent three and respondent four, they shared the similar perception toward cooperative learning; the learning style which promote students to work in groups in learning contents or skills.

\section{Levels of Interest Among Participant to Implement Cooperative Learning}

Most of the participants rate themselves as likely to practice the cooperative learning approach in classroom with six participants rate four in a scale 1-5 (very low and very high respectively). There were two respondents which rate themselves three and the other two considered themselves as most likely to adopt cooperative learning in their teaching and learning.

\section{The Advantages of Cooperative Learning}

Most of the respondents agreed cooperative learning approach could help them to improve their teaching and learning and students enhance their learning experience. Consequently, students were more likely to enjoy learning and achieve success during examinations. 


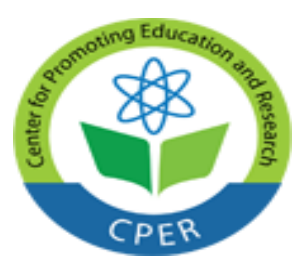

VOL: 5, ISSUE: 3

March/2019

E-ISSN: 2469-6501

(C) Center for Promoting Education and Research (CPER) USA

WWW.cpernet.org

\section{The Effectiveness of Cooperative Learning in Classroom}

Most of the respondents also agreed cooperative learning approach were generally beneficial for both the teachers and students. Nonetheless, there were four respondents suggested the cooperative learning would not guaranteed to improve the teaching and learning process.

\section{Discussion}

Both Ozgul et al., (2019) and Huang et al., (2017) explained the cooperative learning were hugely capable of shifting education from the teacher-centered into student-centered teaching and learning. Many of the respondents consistently pointed out the higher learning ownership given to the students enable them to spend more time in observing and evaluating students' learning. Additionally, students were more likely to engaged with the contents and their peers during teaching and learning compared to the previous spoon-fed culture. Besides that, the teacher as a facilitator was crucial to develop confidence and reduce the fear of failure among student especially when learning new contents (Huang et al., 2017).

According to Dyson et al., (2004), the cooperative learning was beneficial to promote wholly student development (i.e., psychomotor, cognitive, affective). This were reflected in this study; for instance, respondent one suggested cooperative learning improves the students' confident levels and their critical thinking. Respondent three and four also believed the approach help student to be more independent learners and work closely with their peers to understand the contents better or solving an issue. This study also reflected on Johnson and Ward (2001) when respondent seven suggested "the task given was discussed among students thus helping me to save time and better prepare for the next session". He also added "problems were solved easier when the students cooperate with their peers and they enjoyed the process of learning".

Nonetheless, there were some respondents suggested cautions in using cooperative learning and the approach would not guarantee improvement in teaching and learning. For instance, respondent one highlighted some students were struggling to engage with the contents and peers in her class when she adopted the approach. She was required to assist the students by modifying her instructions and expectations when completing the task given. Consequently, this would cause time wastage and reduce teaching and learning in class. These concerns were also highlighted in previous study suggested traditional method were more beneficial in teaching technical contents while cooperative learning was useful in teaching sport tactics and strategies (Karavelioglu, 2012).

Additionally, respondent 10 also added "the approach only effective in certain subject like language; not in some subjects which required calculation and analysing inputs". Some respondents were also concern with monitoring students' learning, off-task behaviors, and capabilities to learn the contents effectively when using cooperative learning approach. Previous study accentuated the importance of practice time, teacher's demonstrations, explanation, and attending to students' learning to promote cooperative learning approach in classroom (Zulkifli \& Kulinna, 2018; Vera, Alvarez, \& Medina, 2008).

\section{Implication for Practice}

Results from this study are important to guide teachers in their planning, delivering contents, and management of classroom. Although, cooperative learning could be useful to promote teaching and learning, teachers need to be aware of their students' strength, weaknesses, and interests to ensure the approach they use is the most suitable for that specific group of students. Teacher should also vary their teaching approach by doing modification on rules, learning area, and instructions based on students' capabilities to ensure meaningful students' learning. Dividing students into teams or partners, present scenarios, fantasy cards, using music as cues are important to promote active students' involvement, enhance learning, and effective practice of skills while maintaining the authenticity of students' learning experience (Zulkifli \& Kulinna, 2018). A few limitations to this study included small sample size, lack of comparison group, and a short study duration. 


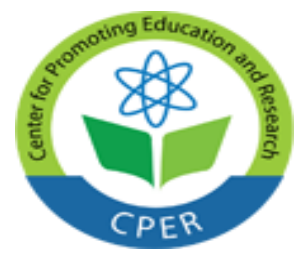

VOL: 5, ISSUE: 3

March/2019

https://ijbassnet.com/

E-ISSN: 2469-6501

(C) Center for Promoting Education and Research (CPER) USA

WWW.cpernet.org

\section{Conclusion}

This study further strengthens the current knowledge on teachers' knowledge and perception on cooperative learning approach in classroom. Furthermore, this study believe that teachers are more willing to shift their approach from teacher-centered toward student-centered when they prioritize their students' learning as well as having supportive administrators and colleague. Nonetheless, cooperative learning might not be the best approach in subjects which focus on calculation and information analysis due to the complexity of the contents and teachers' perceptions on their students' capabilities.

\section{References}

Chai, K. C., Tay, K. M., \& Lim, C. P. (2015). A new fuzzy peer assessment methodology for cooperative learning for students. Applied Soft Computing Journal, 32, 468-480.

Bahadir, Z. (2011). The impact of different teaching methods (cooperative learning and training methods) on student's lesson attitudes and social skills used in physical education and sports (Unpublished doctoral thesis). Gazi University, Ankara, Turkey.

Demirham, G., \& Altay, F. (2001). Attitude scale of high school first graders towards physical education and sport. Hacettepe Journal of Sport Sciences, 12(2), 9-20.

Huang, M. Y., Tu, H. Y., Wang, W. Y., Chen, J. F., Yu, Y. T., \& Chou, C. C. (2017). Effects of cooperative learning and concept mapping intervention on critical thinking and basketball skills in elementary school. Thinking Skills and Creativity, 23(101), 207-216.

Johnson, M., \& Ward, P. (2001). Effects of classwide peer tutoring on correct performance of striking skills in $3^{\text {rd }}$ grade physical education. Journal of Teaching in Physical Education, 20, 247-263.

Karavelioglu, M. B. (2012). Investigation of the effects of specific soccer skills learning of the collaborative teaching methods (Unpublished doctoral thesis). Gazi University, Ankara, Turkey.

McWilliam, L. A., Malecha, A., Langford, R., \& Clutter, P. (2017). Comparisons of cooperative-based versus independent learning while using a haptic intravenous simulator. Clinical Simulation in Nursing, 13(4), 154-160.

Ozgul, F., Atan, T., \& Kangalgil, M. (2019). Comparison of the command and inclusion styles of physical education lessons to teach volleyball in middle school. The Physical Educator, 76, 182-196.

Piaw, C. Y. (2016). Survey research. Mastering Research Methods (pp. 180-187). Malaysia: McGraw-Hill Education.

Vera, J.G., Alvarez, J.C.B., \& Medina, M.M. (2008). Effects of different practice conditions on acquisition, retention and transfer of soccer skills by 9-year old schoolchildren. Perceptual and Motor Skills, 106, 447-460.

Zulkifli, A. F., \& Kulinna, P. (2018). Self-efficacy, soccer skills and the influence on students' learning experience. Biomedical Human Kinetics, 10, 1-7. 